\title{
CIDA adopts new food security strategy
}

Published at www.cmaj.ca on Dec. 11, 2009

$\mathrm{T}$ he Canadian International Development Agency (CIDA) will substantially increase its support for agricultural development projects in response to a food crisis that the United Nations says has pushed the number of hungry people worldwide to well over a billion.

The rationale for the shift is selfevident, says Bev Oda, Canada's minister of international cooperation. "The first order of business has to be keeping people alive."

CIDA announced in May, 2009 that it intends to make food and agriculture a central priority (along with development programs aimed at children and youth, and the promotion of economic growth worldwide). In October 2009, the agency released what it calls its Food Security Strategy.

CIDA will drop all conditions requiring recipients of Canadian food aid to purchase Canadian-grown food, while increasing investments in agricultural development to $\$ 1.2$ billion annually by 2012 - about double the 2008 investment and a 14-fold increase over 2001 levels. CIDA's overall budget is currently $\$ 3.5$ billion. About half of the money for the food security will be new funding directly committed by Prime Minister Stephen Harper at a G8 summit in July 2009.

The money will go to enhance Canada's role as the third-largest contributor to the UN's World Food Programme, which supports famine and hunger relief, as well as to support small farmers through the International Fund for Agricultural Development and through direct partnerships with Canadian groups working to support farmers around the world.

As well as bolstering support for programs like HarvestPlus, which researches nutrition fortification, and the Consultative Group on International Agricultural Research, CIDA plans to establish a Canadian International Food

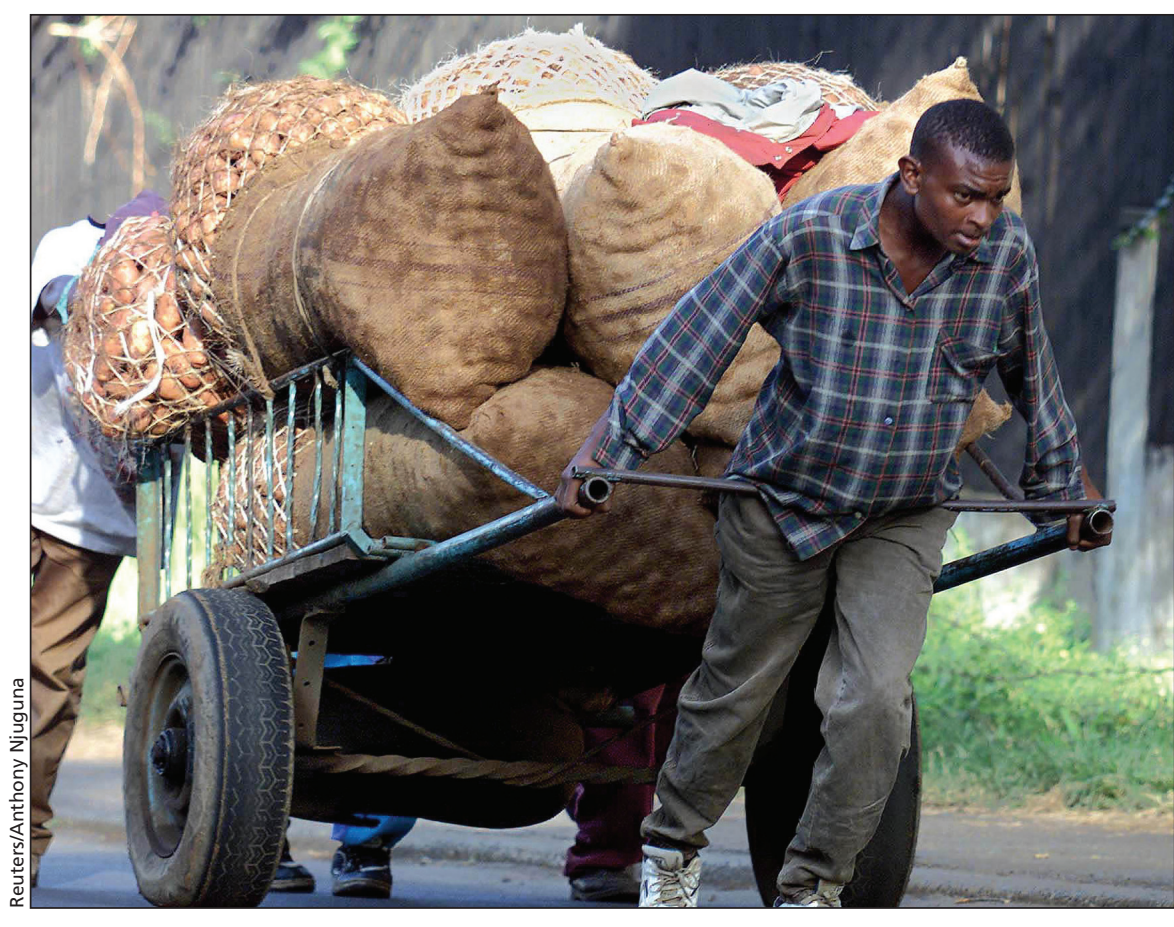

Young men cart sacks of potatoes to market in Nairobi, Kenya.

Security Research Fund to support research on topics such as crop resilience, crop nutrition and infectious diseases related to crops and animal production.

"There's an enormous need and a growing need for food. We see the increase in hunger," Oda says. "When you look at many of the developing countries, they are agricultural-based countries. Agricultural support is not only going to contribute to food security, it's also going to contribute to their economic growth. We've got to ensure there's a good supply of good quality food [that's] going to contribute to the health of people."

Reaction to the CIDA changes among Canadian development workers and analysts has been predominantly enthusiastic.

"We're very pleased," says Mark Fried, Canadian policy director for Oxfam. "We think it's wise to see an emphasis on food security."

"To say I am impressed is an under- statement," says Anne-Marie Ball, who directs HarvestPlus' Ugandan effort. "This is welcome news indeed."

In Winnipeg, Paul Hagerman, policy director for the Canadian Foodgrains Bank and chair of the Food Security Policy Group, which includes 15 development organizations, says the new CIDA strategy seems to be "largely positive." But he adds that details are sparse, beyond the short statement titled CIDA's Food Security Strategy at a Glance (www.acdi-cida .gc.ca/acdi-cida/ACDI-CIDA.nsf/eng /NAT-1016105724-KJX ).

"We like what we see, but we don't see much," Hagerman says. "And I'm not sure just how worrying that is. We'd like to see this directed to projects appropriate for small-scale agriculture. But there's not much here to hold them accountable."

Although CIDA states that "emphasis will be placed on ensuring that rural smallholder farmers can contribute to increasing food security," 
Hagerman worries the end result may favour large-scale, export-oriented crop development.

Oda says an implementation plan for the strategy is being developed. She adds that she herself "has been asking for an update." But Oda pledges that plans will be "directly shaped by" legal requirements that Canadian aid be directed to the poor, and that money within the strategy will be "directly earmarked for small-holders."

Although the minister's message matches longstanding calls from Oxfam, Canadian Foodgrains Bank and other development groups, concerns about internal disarray within CIDA remain acute.

In a report issued in November 2009, the auditor general of Canada noted that new plans being formulated within CIDA "remain unclear" and have not "received formal approval or been communicated broadly within CIDA. None have been made public. This means that donors, recipient governments, and program staff are unclear about the agency's direction and longterm commitment to specific countries or regions."
The auditor general characterized CIDA as an agency where "intentions were not matched with specific action plans and follow-through," and that "has yet to develop a comprehensive strategy for implementing its commitments." In addition, the auditor general observed, "frequent changes in policy direction and substantial turnover of senior personnel in recent years have posed significant challenges for CIDA's aid effectiveness agenda."

With global warming now identified by the United Nations as a driving

\section{Biofortified potato}

Christine Omagor, a Ugandan potato farmer with four children to feed in Koena, a village of mud huts surrounded by intensively cultivated fields, quips that her life was changed forever by a foreigner, to wit, a potato.

For decades, Omagor grew white potatoes of a type common throughout East Africa, where potatoes, corn and beans provide bare subsistence for tens of millions of villagers.

Three years ago, though, a team of Ugandan, Canadian and American scientists introduced an orange-coloured sweet potato, containing far higher levels of vitamin A, to 10000 farmers.

The experiment has been an enormous success, says Omagar. "Before they brought these potatoes, our children were weak; they were sickly. But now they can take four months, maybe six, without getting malaria. So we know this potato is helping us with our children."

The potato, now known colloquially as "Vitamin A," was bred from Peruvian stock by Uganda's National Agricultural Research Organization with support from researchers with HarvestPlus, a research group with offices in Washington, DC, and Ottawa, Ontario, that specializes in breeding new crop varieties fortified with vitamin $\mathrm{A}$, zinc and iron.

The potato project is one of a leading edge of initiatives to breed and introduce enriched staple foods — including wheat, rice, cassava, corn and pearl millet — and thereby substantially alleviate malnutrition, says Erick Boy, HarvestPlus's Ottawa, Ontario-based director of nutrition research.

Boy adds studies also indicate that such biofortified crops could substantially reduce vulnerability to common killers such as malaria, pneumonia and diarrhea.

Undernutrition is estimated to cause the deaths of 3.5 million children, or almost a third of all deaths among children under age five, and contribute to the death of 100000 mothers annually. An estimated 125 million children suffer from vitamin A deficiency. As a result, 14 million children are estimated to have seriously impaired vision or blindness. Canada is the world's leading donor for vitamin A programs.

Recent research shows a strong link between vitamin A deficiency and the severity of HIV/AIDS (Vitam Horm 2007; 75:355-83). An adequate supply of vitamin A could reduce child mortality by as much as $20 \%$ - representing a total of about 1.5 million lives annually — in the countries where the deficiency is most prevalent, says Anna-Marie Ball, a Canadian specialist in African public health who directs HarvestPlus' Ugandan effort.

"The initial cost of developing biofortified crops is in the plant breeding and that's very expensive. But it's a one-time cost," she says. "We want to introduce the biofortified beans high-zinc and high-iron beans. That combination of the beans and the sweet potatoes really gives families a fighting chance."

Biofortified crops have been under development for more than a decade at research institutes in Africa, Latin America and Asia operated by the Consultative Group on International Agricultural Research, a food research network that has received almost \$1 billion from CIDA since the 1970s.

The vitamin A potato project is a crucial test, Ball says. "Our research indicates that Ugandan farmers will accept the new crop and that once consumers learn that they bring substantial health benefits, they will buy and eat these potatoes. This could bring a major advance in a long-running effort to get more nutritious food to the world's neediest people."

Not only are the vitamin A potatoes healthier, Christine Omagor enthuses, they are remarkably drought resistant. That's vitally important, given that her district borders on a region of Africa in which prolonged drought has triggered a food crisis that threatens an estimated 23 million.

Recent summers have been long and hot, Omagor notes. This year, there was no rain for almost four months. "The vitamin A potatoes grow better than the white potatoes when there is little rain," Onager says, so she can feed her family and perhaps someday even crack the market in Kampala and other cities, which would pay for school fees and maybe even help to fulfill her dream of moving the family from a hut to a bigger house.

"We want to grow it," she says. "If there is a market we shall grow it in plenty." - Paul Webster, Koena, Uganda 
force in agricultural disruption leading to food scarcity in sub-Saharan Africa and elsewhere, Oda also noted that climate change will assume a "big role in our agricultural work," including a \$100-million fund aimed at reducing vulnerability to climate change.

The emphasis will be on helping farmers adapt to "a reality you have to address" through programs designed to reduce vulnerability rather than through programs aimed at climate change mitigation, she adds.

Tony Weis, an agricultural economics specialist at the University of Western Ontario in London would like to see still more support for climate change adaptation accompanied by a domestic commitment to emissions reductions. "If we had a more responsible climate policy at home, we could have a more responsible development strategy," he argues.

Inconsistencies among federal policies relating to international food security are also a concern among analysts who track Canada's agricultural trade. With the bulk of hunger and food scarcity in the world linked to imbalances in international trade that curtail food production in poor countries, many analysts say Canadian policies aimed at promoting unfettered food exports do far more harm than any good that will flow from CIDA's new food security strategy.

"As a junior ministry, CIDA is invited to keep its mouth shut about trade policy," says Stuart Clark, a trade analyst with the Canadian Foodgrains Bank. CIDA efforts to promote smallholder farming in countries with growing domestic markets "could be in conflict" with Canadian efforts to promote exports to those countries.

Matias Margulis, a former federal trade policy adviser and delegate to the World Trade Organization, says Canada has aggressively blocked efforts by poor countries to protect their domestic farmers. "When it comes to international trade we're not one of the good guys," he notes, adding that a \$500-million federal subsidy for the production of fuel from food crops - which critics say amounts to a huge subsidy for Canadian producers - is also inconsistent with the new CIDA food security strategy. Many analysts say biofuel production is a leading cause of the food crisis that drove hundreds of millions into hunger.

Before Canada can help poor countries achieve food security, "agricultural corporations need to stop pressuring Ottawa to promote exports at any cost," says Darrin Qualman, director of research for the National Farmers Union office in Saskatoon, Saskatchewan. "Any good that can be done by agricultural aid is quickly undone by the very aggressive policy of exporting, which destabilizes small farmers around the world." - Paul Christopher Webster, Koena, Uganda

DOI: $10.1503 / \mathrm{cmaj} .109-3137$ 